\title{
A wood gasification stove for domestic use: Design, performance and emission factors
}

Gerrit Kornelius, Stefan Kruger, Ruan Fouchee and Hendrik van Wyk ${ }^{1}$

Environmental Engineering Group, Department of Chemical Engineering, University of Pretoria, Pretoria, 0002, gerrit.kornelius@up.ac.za

\begin{abstract}
It has been shown that large numbers of low-income SA households use wood for domestic cooking and spaceheating purposes and are exposed to high concentrations of air pollutants emitted from the unsophisticated appliances being utilised. Although the related problem of exposure to coal smoke from domestic fires has been and is being addressed, wood smoke exposure remains a pressing problem. The design of a more efficient wood using appliance therefore has the potential to reduce the particulate matter exposure of a considerable portion of the SA population. This paper presents the design of a natural draft wood gasification stove for domestic use based on the inverted downdraft principle. Prototypes have been built in two sizes, suitable for relatively unsophisticated manufacturing techniques. The results of performance testing as well emission factor determination are presented. It is shown that simple wood gasification stoves can at least be used for cooking, with a considerable reduction in exposure of household members to particulate matter inhalation.
\end{abstract}

Keywords: domestic energy supply, inverted downdraft wood gasification, wood stove emission factors

\section{Introduction}

The largest contribution to air pollution in dense, lowincome communities in South Africa is caused by the use of wood and coal in urban areas on the Highveld and use of wood in rural areas for space heating and cooking, although electricity and paraffin are preferred by many of the same households for cooking. Colder areas and colder periods are associated with higher levels of solid fuel use and an increase in air pollution. Coal use is the most significant contributor to health impacts from air pollution in the urban areas (FRIDGE 2004). However, the majority of wood users (about $95 \%$ of wood users or 2.47 million households) live in rural areas.

Data on the use of wood and other biomass in both rural and urban households has attracted considerable interest in the research literature (e.g. Kimemia et al 2011, Adkins et al 2012); in addition to the extensive use of energy in rural areas, it has been shown that there is considerable use of wood even in urban areas (Kimemia \& Annegarn 2011). The choice of energy carrier is not only determined by availability (about $80 \%$ of households have access to electricity) but also by the absolute cost and cost-efficiency of appliance systems (Friedl et al. 2008, 2009). It has however been shown that the particulate matter (PM) emission factors for the use of wood, whether calculated per $\mathrm{kg}$. of fuels used or per unit energy delivered is considerably higher than for coal (FRIDGE 2004). This paper reports on the development of a natural draft wood gasification stove for domestic use to reduce this emission factor.

\section{Methodology}

\subsection{History of wood gasification}

Gasification of wood and coal was known and used since 1800 , with major applications of so called gaslight" in London and Paris during the 1850s. The first large scale application of woodgas generators occurred during World War II when petroleum shortages forced road transport users in Western Europe to find alternative fuels for their vehicles. These $5-100 \mathrm{~kW}$ gasifiers were of the conventional downdraft type where air is forced down through the packed bed of fuel. The volatiles and tars are burnt while charcoal and woodgas are made. (Reed et al., 2000; Reed \& Larson, 1996).

If a packed volume of fuel is ignited from the bottom, it is referred to as an updraft gasifier. The biggest drawback of updraft gasification is the large amount of tar produced while consuming the charcoal residue, which renders it unsuitable for cooking purposes. For a woodgas stove to work using only natural convection, it needs to be an inverted downdraft gasifier which is ignited at the top. The primary air enters at the bottom and moves up through the packed bed of fuel with a draft of approximately $100 \mu \mathrm{m}$-water pressure due to the buoyancy of the $500^{\circ} \mathrm{C}$ pyrolysis gas (Reed \& Larson, 1996). Secondary air is then allowed to mix with the woodgas to prepare the fuel/air mixture necessary for combustion.

\subsection{Design}

Based on work by Anderson and Reed (2004) and an existing forced draft camping stove design, two versions of inverted downdraft wood gasifier estimated to be able to boil a litre of water in ten minutes, thus allowing cooking on limited scale, were manufactured and tested (figures 1 and 2 below). In the first version, gasification takes place in the inner sleeve while mixing of the gas and secondary air 
takes place in the outer sleeve. In the second, gasification takes place in the bottom section while mixing with secondary air and combustion takes place in the top section. Practical experience as well as the ease of adjusting both primary air (as shown in the bottom view in figure 2) and secondary air (by adjustment of the gap between the bottom and top sections), which is not easily done on the "sleeve stove", lead to the adoption of the double volume stove for scaling up to an outer diameter of $220 \mathrm{~mm}$ and a cross-sectional area three times that of the smaller model.

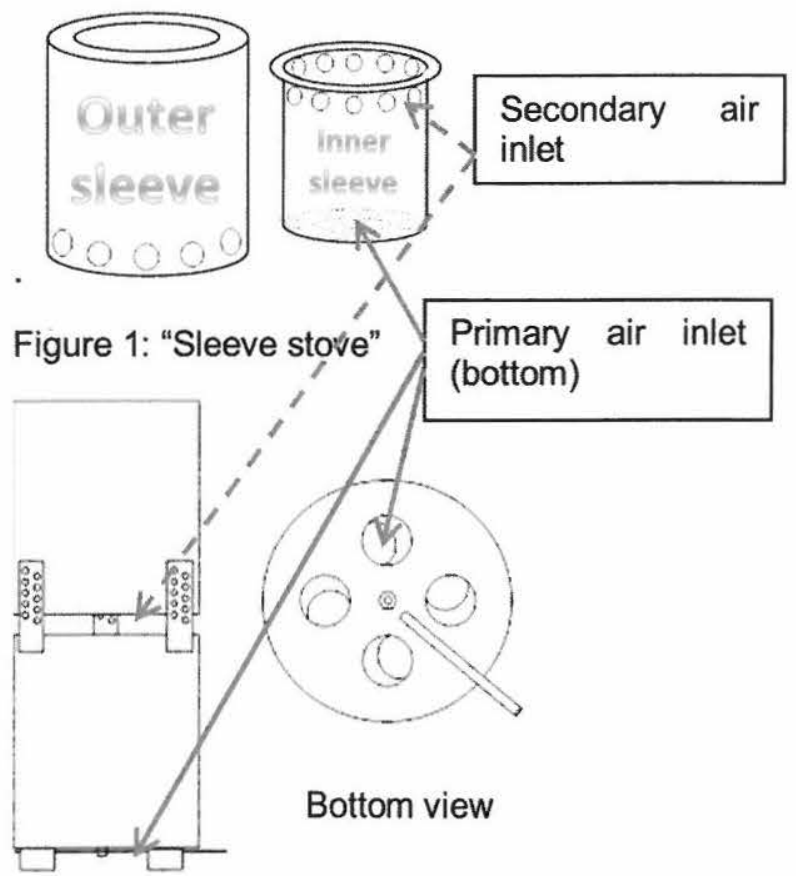

Figure 2: "Double volume stove"; gasification in the lower section, combustion of gas in the upper.

The use of an outer sleeve made of light galvanised sheet around the lower (gasification) section of the scaled-up "double volume" model showed some promise with regards to protection against injuries and the pre-heating of combustion air, but needs further development.

\subsection{Fuels}

The three types of fuel tested were industrial wood waste (wood shavings), pine woodchips and sickle bush firewood chopped to the desired dimensions as proposed by Anderson \& Reed (2004). For tinder a small amount of ethanol gel was initially used as this does not drip and promotes quick lateral distribution of the fire on the fuel bed surface. Due to the limited availability of ethanol gel, subsequent tests using newspaper layers over the top of the wood bed showed that this also provided a suitable tinder.

It was soon found that the industrial wood shavings did not allow for sufficient bed porosity and had too high a moisture content to allow consistent gasification without forced draught and further work was done with approximately uniform pine wood cubes with $1 \mathrm{~cm}$ sides providing a bulk density of approximately $180 \mathrm{~kg} / \mathrm{m}^{3}$, although this does not rule out the use of indigenous species, which would probably provide a higher bulk density.

\section{Testing}

\subsection{Performance (small scale)}

Practical energy output was measured by plotting the temperature change of water in a suitably sized container being heated on the stove. For the upscaled double volume stove, emissions factors were determined by operating the stove under a hood with a chimney and using flow measurement by vane anemometer through the chimney, with Dräger tubes used for gas concentration measurements and a Dustrak laser particle counter with a $10 \mu \mathrm{m}$ impactor used for particle concentration measurement. The total amount of the pollutants could be determined in this way and normalised to the fuel mass used and the energy output.

Adjustment of the primary and secondary air supply openings to provide the highest rate of heating combined with a visibly clean flame provided typical results given in figure 3 below for the smaller scale double volume stove.

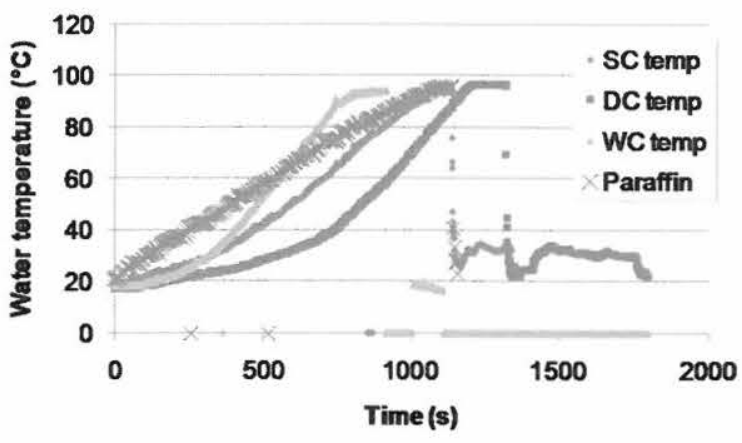

Figure 3: Temperature (of the water) vs time curves for the sleeve stove (SC), double volume stove (DC), forced draft camping stove (WC) all using pine cube fuel and a comparative commercial paraffin stove.

Plotting the slope of the lines in figure 3 produces practical power outputs given in table 1 below.

\begin{tabular}{|l|c|}
\hline \multicolumn{1}{|c|}{ Type } & Output (kw) \\
\hline FD camping stove & 1.18 \\
\hline Double volume & 1.02 \\
\hline Sleeve stove & 0.76 \\
\hline Paraffin stove & 0.58 \\
\hline
\end{tabular}

Table 1: Small-scale stove practical output.

All of these stoves are capable of boiling a litre of water in less than 10 minutes using pine cubes in a batch mode. The intermittent feeding of additional 
wood cubes has been tested and has shown the potential to considerably extend operational time without causing upsets in operational conditions. Preliminary testing of $\mathrm{CO}$ and NOx concentrations indicated that the natural draught produced considerably higher $\mathrm{CO}$ and $\mathrm{NO} x$ concentrations than the forced draught prototype, indicating inferior gasification and mixing of gas and secondary air compared to the forced draft model.

\subsection{Performance (upscaled)}

Performance results at the optimum settings of the larger-scale stove, determined from the temperature vs time curves of a 4 l container of water are given in figure 4 below. The break in the curves indicates the time where the water was boiling and the container was replaced by one containing water at room temperature. Maximum output was $3 \mathrm{~kW}$ (measured from the slope of the curves) and the average output over the entire $77 \mathrm{~min}$ combustion period was $2.2 \mathrm{kw}$ using a single batch (10l or approximately $1.8 \mathrm{~kg}$ ) of pine cubes.

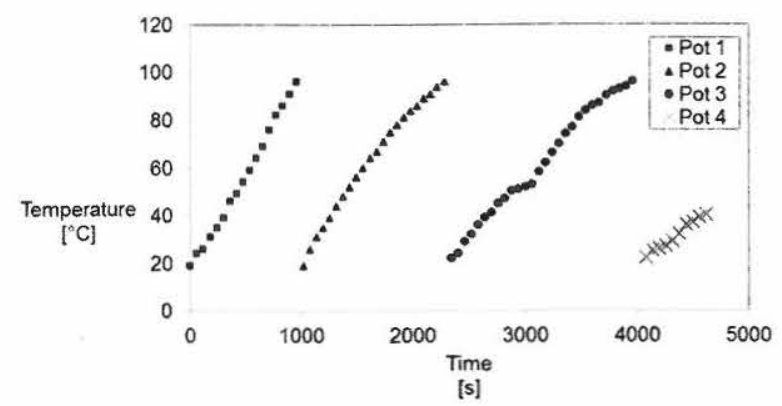

Figure 4: Temperature history for upscaled double volume stove.

\subsection{Emission factors.}

Emission factors were obtained for the optimum run of the upscaled stove as in table 2 below. The figures in the last column are the comparative ones given in (FRIDGE 2004).

\begin{tabular}{|l|c|}
\hline \multicolumn{1}{|c|}{ Pollutant } & $\mathrm{g} / \mathrm{kg}$ of wood used \\
\hline $\mathrm{SO}_{2}$ & $<0.78$ \\
\hline $\mathrm{NOx}$ & 0.23 \\
\hline $\mathrm{PM}_{10}$ & 0.04 \\
\hline $\mathrm{CO}$ & 0.16 \\
\hline
\end{tabular}

\section{Conclusions}

An inverted natural downdraft wood gasification stove that has the potential to be built using readily available local materials has been designed and tested at approximately $1 \mathrm{~kW}$ and $3 \mathrm{~kW}$ practical output levels. This is sufficient for most cooking purposes, while the larger unit has the potential to be used for space heating.

Operation is robust, with the potential for intermittent feeding to extend operating times.

The logistics of fuel supply and preparation, especially using locally available indigenous wood types, requires further investigation.

\section{References}

Adkins, A., Oppelstrup K. and Modi, V.(2012) "Rural household energy consumption in the millennium villages in sub-Saharan Africa". Energy for sustainable development 16 (3) (Sept 2012) pp 249259

Anderson, PS and Reed, TB (2004) "Biomass Gasification: Clean Residential Stoves, Commercial Power Generation and Global Impacts", prepared for the LAMNET Project International Workshop on "Bioenergy for a Sustainable Development", 8-10 November 2004, Vina del Mar, Chile.

FRIDGE 2004, 'Study to examine the potential socioeconomic impact of measures to reduce air pollution from combustion'. Airshed Planning Professionals and Bentley West Management. Consultants for Trade and Industry Chamber/Fund for Research into Industrial Development, Growth and Equity (FRIDGE), Johannesburg

Friedl A., Holm D., John J, Kornelius G., Pauw C.J., Oosthuizen R. and van Niekerk A.S. (2008) 'Air pollution in dense, low-income settlements in South Africa'. Nova Institute for the DEAT on behalf of Royal Danish Embassy.

Friedl A., Holm D., John J, Kornelius G., Pauw C.J., Oosthuizen R. and van Niekerk A.S. (2009) "Air pollution in dense low-income settlements in South Africa." Proceedings, National Association for Clean Air annual conference 2009, Nelspruit.

Kimemia D.K., Annegarn H.J., Makonese V., Molapo v. and Robinson J.(2011) "Characterisation of domestic combustion technologies used in Setswala, Alexandra township, Gauteng", paper presented at the Domestic use of energy conference, Apr 2011, Cape Peninsula University of Technology, Cape Town, South Africa

Kimemia D.K. and Annegarn H.J.(2011) "An urban biomass energy economy in Johannesburg, South Africa". Energy for sustainable development 15 (4) (Dec 2011) pp 382-387

Reed, T.B., Anselmo, E. \& Kircher, K. (2000) "Testing and Modelling the Woodgas Turbo Stove", paper presented at Progress in Thermochemical Biomass Conversion Conference, 17 - 22 September 2000, Tyrol, Austria.

Reed, TB and Larson, R (1996) "A wood-gas stove for developing countries", paper presented at the Developments in Thermochemical Biomass Conversion Conference, 20 - 24 May 1996, Banff, Canada. 